\title{
Pituitary stalk thickening: neoplastic or not? - author's response to the letter by Wang et al.
}

\author{
France Devuyst', Paraskevi Kazakou², Danielle Balériaux³, Orsalia Alexopoulou4, Agnès Burniat', \\ Sylvie Salenave ${ }^{5}$, Philippe Chanson ${ }^{5,6}$, Bernard Corvilain ${ }^{1}$ and Dominique Maiter ${ }^{4}$
}

1Department of Endocrinology, Erasme Hospital, Université libre de Bruxelles, Brussels, Belgium, ${ }^{2}$ Department of Medical Therapeutics, Endocrine Unit, Alexandra Hospital, National and Kapodistrian University of Athens, Athens, Greece, ${ }^{3}$ Department of Neuroradiology, Erasme Hospital, Université libre de Bruxelles, Brussels, Belgium, ${ }^{4}$ Department of Endocrinology and Nutrition, Université catholique de Louvain, Cliniques Universitaires Saint-Luc, Brussels, Belgium, ${ }^{5}$ Assistance Publique-Hôpitaux de Paris, Hôpital de Bicêtre, Service d'Endocrinologie et des Maladies de la Reproduction, Centre de Référence des Maladies Rares de l'Hypophyse, Le Kremlin Bicêtre, France, and ${ }^{6}$ Université Paris-Saclay, Univ. Paris-Sud, Inserm, Signalisation Hormonale, Physiopathologie Endocrinienne et Métabolique, Le Kremlin-Bicêtre, France

Correspondence should be addressed to F Devuyst Email

fdevuyst@ulb.ac.be
We thank Dr Shirui Wang and colleagues for their interest in our recent publication on the distinction of neoplastic from non-neoplastic lesions in adult patients presenting with central diabetes insipidus (CDI) and pituitary stalk thickening (PST) (1). We acknowledge the fact that they could not confirm in their population our previous observation that a higher prolactin (PRL) concentration at diagnosis increases the likelihood of a neoplastic origin (2). As they mentioned, such an association of CDI and PST represents a rare and heterogeneous disorder, raising challenging issues in both diagnosis and management. It is interesting to mention that only 46 out of their original cohort of 321 patients with PST (3) were eligible for this comparative analysis. As there are limited data about the prevalence and significance of hyperprolactinemia in such patients, any additional insight is most welcome and worth to debate.

We want to provide several potential explanations for the discordance observed between their findings and our results. First, the definition of PST was not exactly the same in the two studies. While they used a constant cut-off of PS thickness $\geq 3 \mathrm{~mm}$ along the stalk (3), we rather used differential cut-offs based on the previously reported normal dimensions of the hypothalamic-pituitary axis on MRI $(1,4,5,6,7,8)$. More specifically, the pituitary stalk was considered enlarged when its largest diameter was greater than $4.0 \mathrm{~mm}$ in its proximal portion at the level of the optic chiasm, $2.8 \mathrm{~mm}$ in its medial portion and/or $2.5 \mathrm{~mm}$ in its distal portion at the level of pituitary insertion. This may have led to a slightly different selection of patients, in particular, more severely affected patients at the level of the infundibulum.

We do not believe that gender may have influenced our different results as prolactin concentrations were normalized against sex-specific normal range. However, the upper normal limits (ULN) of prolactin concentrations were not based on the Guidelines of the Pituitary Society (9) but rather on the respective reference ranges given by the different laboratories of the three participating centers. Thus, PRL ULN was $23-25 \mu \mathrm{g} / \mathrm{L}$ in women and $12-15 \mu \mathrm{g} / \mathrm{L}$ in men. Again, this may lead to substantial differences in the relative prolactin levels (xULN), raising them in particular in men who were predominant in the malignant group.

Ethnic differences in PRL concentrations and in PRL response to physiological or pathological conditions may have also affected the results obtained in the different Caucasian and Asian populations, respectively. Such differences have been reported for prolactin. It has been for example reported that Caucasians have a less prominent prolactin response to haloperidol than Asians (10) and that prolactin concentrations may be different between Caucasian and Japanese women at risk for breast cancer (11). (c) 2020 European Society of Endocrinology Printed in Great Britain
Published by Bioscientifica Ltd. 
In patients with PST and CDI, one of the main goals of the medical workup should be to exclude a neoplastic underlying pathology. Others and we showed that PS thickness was slightly larger in patients with malignant disease $(12,13)$ but a large overlap exists with benign lesions, making this criterion of limited use in the differential diagnosis (1). When analyzing the weak correlation between the thickness of pituitary stalk and serum PRL concentration in our series $(r=0.363, P=0.063)$, one can easily observe that prolactin was much higher in most malignant cases than in patients with benign disease, independent of the size of the stalk (Fig. 1). This suggests that the mechanisms of hyperprolactinemia in this setting are not simply related to stalk compression or infiltration but probably also depends on other factors such as cancer-induced structural damage of the tuberoinfundibular neurons. Heterogeneity in the case severity or in the course of the disease could obviously affect such results.

We agree with Wang and colleagues that ongoing controversy subsists regarding the classification of ' $L$ '-type histiocytosis as being a malignant or inflammatory process. Our work did not try to solve this issue and we decided to simply follow the classification proposed by the well-recognized Histiocyte Society (14). We however compared in our paper the specific features

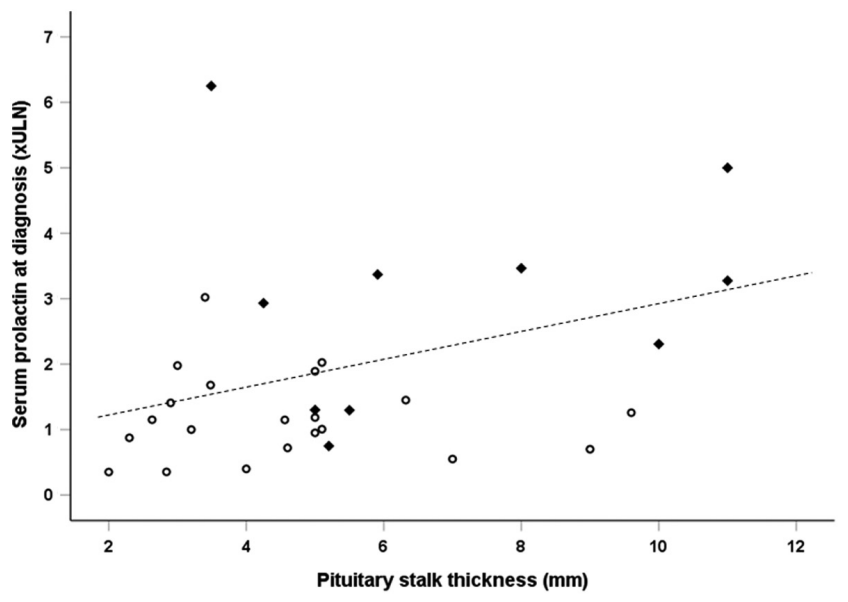

\section{Figure 1}

Correlation between pituitary stalk thickness (maximal diameter measured on a sagittal T1-weighted view on magnetic resonance imaging) and serum prolactin concentration at diagnosis, expressed as a multiple of the upper limit of normal (ULN). Diamonds represent patients with a neoplastic disease while circles represent patients with a benign etiology. The correlation was not significant between the two parameters $(n=31 ; r=0.363, P=0.063)$. of the three most frequently observed etiologies of PST (i.e. neuroinfundibulitis, histiocytosis and germinoma) and we could observe many similarities in the baseline characteristics of the two first subgroups as opposed to the third one.

Finally, we also agree with Wang and colleagues that further studies are needed to validate our findings and to define the best serum prolactin cut-off that will differentiate malignant from benign PST with CDI.

\section{Declaration of interest}

The authors declare that there is no conflict of interest that could be perceived as prejudicing the impartiality of the research reported.

\section{Funding}

This research did not receive any specific grant from any funding agency in the public, commercial or not-for-profit sector.

\section{References}

1 Devuyst F, Kazakou P, Balériaux D, Alexopoulou O, Burniat A Salenave S, Chanson P, Corvilain B \& Maiter D. Central diabetes insipidus and pituitary stalk thickening in adults: distinction of neoplastic from non-neoplastic lesions. European Journal of Endocrinology 2020181 95-105. (https://doi.org/10.1530/EJE-20-0058)

2 Wang S, Zhou X \& Zhu H. Reevaluation of the value of prolactin in differentiating malignant from benign pituitary stalk thickening. European Journal of Endocrinology 183 L19-L21. (https;//doi.org/EJE20-0931)

3 Zhou X, Zhu H, Yao Y, Lian X, Feng F, Wang L, Liu S, Deng K, You H, Yang $\mathrm{H}$ et al. Etiological spectrum and pattern of change in pituitary stalk thickening: experience in 321 patients. Journal of Clinical Endocrinology and Metabolism 2019104 3419-3427. (https://doi. org/10.1210/jc.2018-02297)

4 Simmons GE, Suchnicki JE, Rak KM \& Damiano TR. MR imaging of the pituitary stalk: size, shape and enhancement pattern. American Journal of Roentgenology 1992159 375-377. (https://doi.org/10.2214/ ajr.159.2.1632360)

5 Raveendranath V, Nagarajan K, Umamageswari A, Srinidhi S \& Kavitha T. Three-dimensional magnetic resonance-based morphometry of pituitary stalk. Radiologia Medica 2019124 206-210. (https://doi.org/10.1007/s11547-018-0956-6)

6 Satogami N, Miki Y, Koyama T, Kataoka M \& Togashi K. Normal pituitary stalk: high-resolution MR imaging at 3T. American Journal of Neuroradiology 201031 355-359. (https://doi.org/10.3174/ajnr.A1836)

7 Tien RD, Newton TH, McDermott MW, Dillon WP \& Kucharczyk J. Thickened pituitary stalk on MR images in patients with diabetes insipidus and Langerhans cell histiocytosis. American Journal of Neuroradiology 199011 703-708.

8 Catford S, Wang YY \& Wong R. Pituitary stalk lesions: systematic review and clinical guidance. Clinical Endocrinology 201685 507-521. (https://doi.org/10.1111/cen.13058)

9 Casanueva FF, Molitch ME, Schlechte JA, Abs R, Bonert V, Bronstein MD, Brue T, Cappabianca P, Colao A, Fahlbusch R et al. Guidelines of the pituitary society for the diagnosis and management of prolactinomas. Clinical Endocrinology 200665 265-273. (https:// doi.org/10.1111/j.1365-2265.2006.02562.x)

10 Lin KM, Poland RE, Lau JK \& Rubin RT. Haloperidol and prolactin concentrations in Asians and Caucasians. Journal 
of Clinical Psychopharmacology 19888 195-201. (https://doi. org/10.1097/00004714-198806000-00008)

11 Hill P, Wynder EL, Kumar H, Helman P, Rona G \& Kuno K. Prolactin levels in populations at risk for breast cancer. Cancer Research 1976 36 4102-4106.

12 Sbardella E, Joseph RN, Jafar-Mohammadi B, Isidori AM, Cudlip S \& Grossman AB. Pituitary stalk thickening: the role of an innovative MRI imaging analysis which may assist in determining clinical management. European Journal of Endocrinology 2016175 255-263. (https://doi.org/10.1530/EJE-16-0455)
13 Lee JY, Park JE, Shim WH, Jung SC, Choi CG, Kim SJ, Kim JH \& Kim HS. Joint approach based on clinical and imaging features to distinguish non-neoplastic from neoplastic pituitary stalk lesions. PLOS ONE 201712 e0187989. (https://doi.org/10.1371/journal. pone.0187989)

14 Emile JF, Abla O, Fraitag S, Horne A, Haroche J, Donadieu J, RequenaCaballero L, Jordan MB, Abdel-Wahab O, Allen CE et al. Histiocyte Society. Revised classification of histiocytosis and neoplasms of the macrophage-dendritic cell lineages. Blood 2016127 2672-2681. (https://doi.org/10.1182/blood-2016-01-690636)

Received 13 September 2020

Accepted 23 September 2020 